\title{
Fumigation Toxicity of Essential Oil Monoterpenes to Callosobruchus maculatus (Coleoptera: Chrysomelidae: Bruchinae)
}

\author{
Olufunmilayo E. Ajayi, ${ }^{1,2}$ Arthur G. Appel, ${ }^{1}$ and Henry Y. Fadamiro ${ }^{1}$ \\ ${ }^{1}$ Department of Entomology and Plant Pathology, Auburn University, 301 Funchess Hall, Auburn, AL 36849-5413, USA \\ ${ }^{2}$ Department of Biology, Storage Technology Programme, Federal University of Technology, PMB 704, Akure 34001, Nigeria \\ Correspondence should be addressed to Olufunmilayo E. Ajayi; ajfumeu68@yahoo.com
}

Received 19 June 2014; Revised 8 September 2014; Accepted 22 September 2014; Published 7 October 2014

Academic Editor: Fedai Erler

Copyright (C) 2014 Olufunmilayo E. Ajayi et al. This is an open access article distributed under the Creative Commons Attribution License, which permits unrestricted use, distribution, and reproduction in any medium, provided the original work is properly cited.

\begin{abstract}
The fumigant toxicity of eight essential oil components, 1-8-cineole, carvacrol, eugenol, (-)-menthone, (-)-linalool, S-(-)limonene, (-)- $\beta$-pinene, and (+)- $\alpha$-pinene, was tested against the cowpea weevil, Callosobruchus maculatus (Fabricius) (Coleoptera: Chrysomelidae), at $0.25-60 \mu \mathrm{L} / \mathrm{L}$ air doses. 1-8-Cineole, carvacrol, and eugenol caused complete adult mortality at $10 \mu \mathrm{L} / \mathrm{L}$ air $24 \mathrm{~h}$ after treatment. 1-8-Cineole and carvacrol were the most toxic with $\mathrm{LD}_{50}$ values of 0.24 and $0.6 \mu \mathrm{L} / \mathrm{L}$ air at $24 \mathrm{~h}$, respectively. (-)- $\beta$ Pinene and (+)- $\alpha$-pinene were the least toxic with $\mathrm{LD}_{50}$ values of 31 and $31.4 \mu \mathrm{L} / \mathrm{L}$ air at $24 \mathrm{~h}$, respectively. Toxicity was negatively correlated with vapor pressure. 1-8-Cineole and carvacrol caused 100\% oviposition deterrence at all doses tested. Eugenol and (-)menthone completely inhibited adult emergence. $S$ - $(-)$-Limonene, $(-)-\beta$-pinene, and $(+)-\alpha$-pinene were not effective at preventing oviposition or adult emergence, suggesting that a lethal dose of the three oil components would be necessary to control $C$. maculatus infestations.
\end{abstract}

\section{Introduction}

Cowpea, Vigna unguiculata (L.) (Walp.), is an important food legume for millions of people throughout the semiarid regions of Africa, Asia, southern Europe, and North, Central, and South America [1]. The cowpea seed weevil, Callosobruchus maculatus (F.) (Coleoptera: Chrysomelidae: Bruchinae), is the major pest of stored cowpea seed in the tropics and subtropics due to the favorable climatic conditions $[2,3]$. The insect infestscowpeas in the field and the subsequent population buildup in storage can cause complete weight loss of stored cowpeas within six months if no prophylactic measures are put in place [4]. Life history and development of this insect on cowpeas have been described in early studies $[2,5]$.

Stored grain pest control has relied mainly on synthetic chemicals most of which pose serious dangers to life and the environment. Many organochlorine and organophosphate chemicals are already banned, while the use of some is being restricted [6]. The use of methyl bromide, a major fumigant to control pests, is highly restricted [7]. Inhalation of phosphine gas, another grain fumigant, has been implicated in many human health problems [8]. Human health and environmental problems caused by synthetic pesticides, coupled with insects developing resistance to these chemicals, [9] have led to the need for alternative strategies that are ecofriendly and less prone to the development of resistance by pests [10]. Fumigation is still the most effective method of eliminating insect pests in stored products including cowpeas. The concern about the danger in the use of fumigants like methyl bromide and sulfuryl fluoride in pest control has shifted attention to evaluating essential oils as an effective and ecofriendly alternative [11].

An emerging pest control tactic for stored product pests is the use of essential oils. Essential oils are composed of complex mixtures of monoterpenes, biogenetically related phenols, and sesquiterpenes obtained from plants through steam distillation [12]. 
Many studies have demonstrated contact and fumigant toxicity of plant essential oils and their components to several species of stored product insects at different life stages $[13,14]$. Suthisut et al. [15] reported on the toxicity of essential oils of Alpinia conchigera (Griff), Zingiber zerumbet (L.) Roscoe ex Sm, Curcuma zedoaria (Christm.) Roscoe, and their components to Sitophilus zeamais (L.) and Tribolium castaneum (Herbst.). Various essential oils havealso been tested against C. maculatus [16-18]. For example, Hura crepitans (L.) seed oil was reported as toxic to adult and immature stages of C. maculatus [16]. Similarly, oil of Ziziphora clinopodioides (Boiss) caused significant adult and egg mortality [17]. The majority of the above studies on the toxicity of essential oils against C. maculatus tested crude essential oils rather than individual synthetic compounds, making it difficult to attribute toxicity or oviposition deterrence to particular components. Furthermore, most of the studies did not determine the fate of eggs laid during fumigation (i.e., larval development and adult emergence from eggs laid during fumigation with the essential oils).

The objective of this study was to test the fumigant toxicity of some selected essential oil components at low concentrations against $C$. maculatus. The essential oil components tested in this study were chosen because they are major constituents of essential oils that have been found to have high pesticidal properties against store product pests, and the pure forms have also been reported toxic to some stored grain pests [12, 19-21]. Many essential oil components are known neurotoxins [20, 22-24]. We hypothesized that fumigation with low concentrations of the essential oil components will affect the nervous system of $C$. maculatus and thus prevent egg laying on stored seeds. A second hypothesis was that the efficacy of the essential oil components as fumigants is related to their physical properties. First, the fumigant toxicity of the oil components to adult C. maculatus was determined in fumigation chambers. The ability of females to lay viable eggs during fumigation was then assessed using the number of eggs laid. The fate of the eggs laid during fumigation was also determined by recording adult emergence. Finally, toxicity of the essential oil components was correlated with some physical properties of the oil components to identify the factors that best predict toxicity.

\section{Materials and Methods}

Eight essential oil components, 1-8-cineole, carvacrol, eugenol, (-)-menthone, (-)-linalool, $S$-(-)-limonene, (-)- $\beta$ pinene, and $(+)-\alpha$-pinene, obtained from Sigma-Aldrich (St. Louis, MO) were tested in the study. The purity of the oil components ranged between 95 and 99\%.

2.1. Cowpea Seed and Insect Culture. Cowpea (cultivar California black-eye) seeds were purchased from a local grocery store in Auburn, AL, USA. The seeds were kept in polythene bags, sealed and kept in a freezer maintained at $-20^{\circ} \mathrm{C}$ for 72 hours until they were used for insect cultures or the bioassays [25].

A fresh culture of C. maculatus was started from a colony that had been maintained in the laboratory for over 50 generations by placing 25 pairs of 2-day-old male and female beetles in 1-L wide-mouthed glass Mason jars containing $100 \mathrm{~g}$ of cowpea seeds. The jars were placed in a rearing chamber maintained at $28 \pm 2^{\circ} \mathrm{C}, 70 \pm 5 \% \mathrm{r} . \mathrm{h}$, and $12: 12 \mathrm{~h}$ photoperiod $[16,26]$. The beetles were sexed using the keys described by Rees [27]. Female beetles were allowed to lay eggs on the seeds for 24 hours after which they were removed. The seeds containing eggs were kept in a rearing chamber until adult emergence.

2.2. Fumigation with Essential Oil Components. The fumigant toxicity of eight essential oil components at $0.25,5,10,20$, 40 , and $60 \mu \mathrm{L} / \mathrm{L}$ was investigated by exposing five pairs of 1-day-old adult male and female C. maculatus to vapors from the oil components in $1 \mathrm{~L}$ wide-mouthed glass Mason jars containing $20 \mathrm{~g}$ of cowpea seeds. Jars without essential oil components served as the controls. Each treatment was replicated four times. The fumigation lasted for 24 hours at abovementioned environmental conditions. Data on adult mortality was recorded as a percentage of the total number of the beetles fumigated.

Data were arcsine transformed and analyzed using oneway analysis of variance (ANOVA). Tukey's HSD test was used to separate the means. Regression analysis was used to estimate $\mathrm{LD}_{50}$ in the adult mortality tests [28]. Stepwise multiple linear regression was used to reveal the physical property of the oil components that predicts $\mathrm{LD}_{50}$.

To determine the effects of fumigant toxicity of the essential oil components on oviposition deterrence, the number of eggs on all cowpea seeds in each replicate was recorded after fumigation test. The egg-bearing seeds were returned back to the jars and placed in the rearing chamber undisturbed for four weeks after which they were examined for adult emergence. Adult emergence was monitored daily for 10 days starting from 30 days after treatment. Data on adult emergence were used to determine the fate of the eggs laid during fumigation. Logarithmic transformation was performed on oviposition deterrence and adult emergence data. ANOVA and Tukey's HSD test were used to compare the number of eggs laid and number of adults that emerged. All statistics were done using SPSS at $\alpha=0.05$.

\section{Results}

3.1. Fumigant Toxicity to Adults. No mortality was observed in untreated controls during this study. The effect of the tested eight essential oil components on the survival of adult C. maculatus was concentration dependent. Three essential oil components, 1-8-cineole, carvacrol, and eugenol, caused $\geq 90 \%$ mortality to adult beetles at doses of as low as $5 \mu \mathrm{L} / \mathrm{L}$ of air within 24 hours. (-)-Menthone, (-)-linalool, $S$-(-)limonene, and the two structural isomers of pinene also caused $100 \%$ mortality to adult beetles, but at significantly greater doses (20 $\mu \mathrm{L} / \mathrm{L}$ and above) (Figure 1$)$.

The $\mathrm{LD}_{50}$ values obtained in this study (Figure 2) were step-wisely regressed with the density, boiling point, and vapor pressure of the oil components. The analysis revealed vapor pressure as the physical property of the essential oil components that best predicts the $\operatorname{LD}_{50}\left(F_{1,30}=72.57\right.$, 


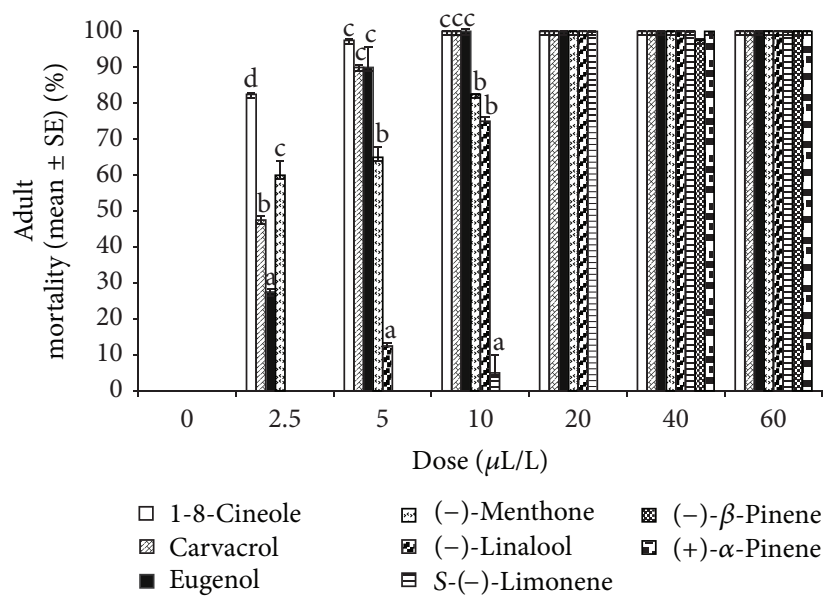

Figure 1: Mortality of adult C. maculatus exposed to eight essential oil monoterpenes.
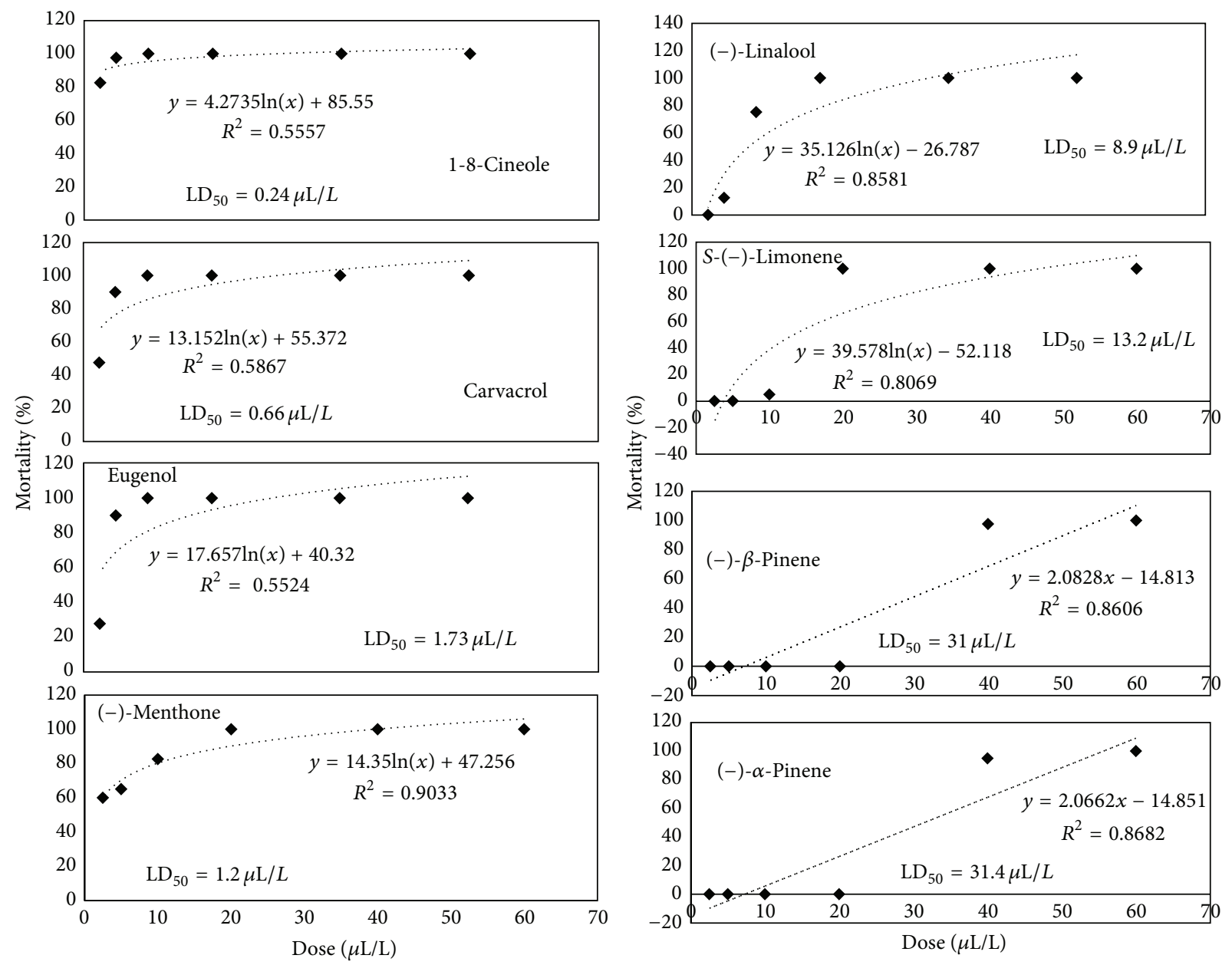

FIGURE 2: Dose-response curves of eight monoterpenes tested against C. maculatus.

$P=0.001)$ and accounted for over $70 \%$ of the variances. In general, toxicity was negatively correlated with vapor pressure (Figure 3). Based on the regression analysis, the predicted $\mathrm{LD}_{50}$ of essential oils can be calculated as follows:

Predicted $\mathrm{LC}_{50}=13.044 \times$ vapor pressure +3.081 .
3.2. Oviposition Deterrence and Adult Emergence. 1-8Cineole and carvacrol completely deterred oviposition at all doses tested (Figure 4). Numbers of eggs laid decreased with increasing dose for eugenol, (-)-menthone (-)-linalool, $S$-(-)-limonene, and the two structural isomers of pinene. 


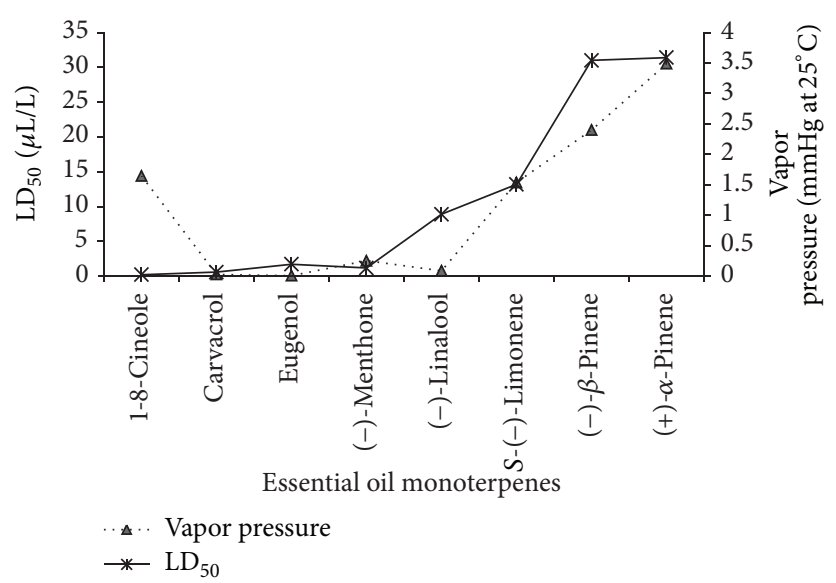

FIgURE 3: Relationship between $\mathrm{LD}_{50}$ and vapor pressure of eight essential oil monoterpenes tested against C. maculatus.

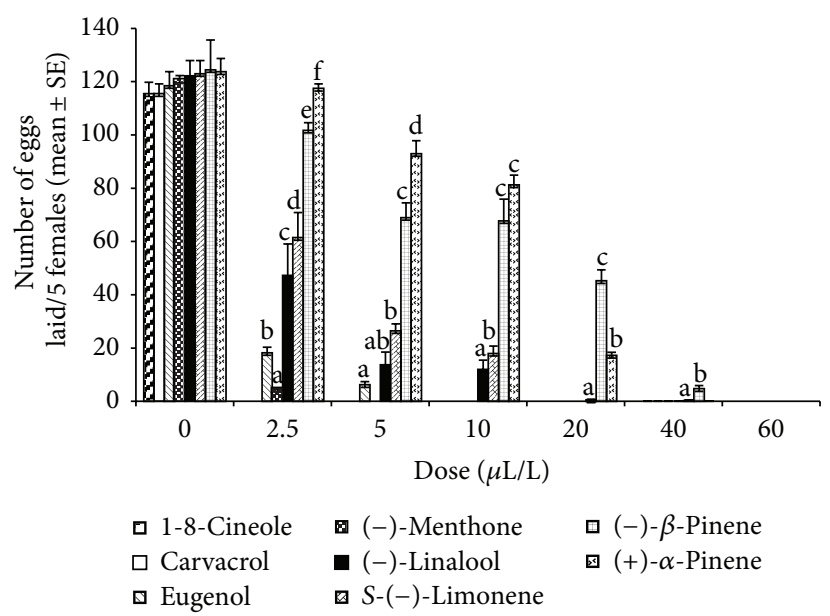

Figure 4: Number of eggs laid by C. maculatus during fumigation with essential oil monoterpenes. ANOVA and Tukey's HSD compared monoterpenes at each dose tested.

and 6.25 eggs at 2.5 and $5.0 \mu \mathrm{L} / \mathrm{L}$, respectively. The two isomers of pinene had significantly higher numbers of eggs compared to (-)-linalool and $S$-(-)-limonene. All eight essential oil components caused $100 \%$ oviposition deterrence at the highest dose tested $(60 \mu \mathrm{L} / \mathrm{L})$ (Figure 4$)$.

Among the oil treatments which did not completely prevent oviposition, eugenol and (-)-menthone completely inhibited adult emergence at all doses tested (Figure 5). Adult emergence decreased with increasing dose of $(-)$-linalool, $S$ $(-)$-limonene, and the two pinene isomers (Figure 5). Adult emergence in seeds treated with $(+)-\alpha$-pinene and $(-)-\beta$ pinene was significantly $(P=0.001)$ higher than in linalool and $S$-(-)-limonene, at $0.25-20 \mu \mathrm{L} / \mathrm{L}$ air (Figure 5).

\section{Discussion}

4.1. Fumigant Toxicity to Adults. The results of this study demonstrated fumigant toxicity of some essential oil components to C. maculatus. Three compounds, 1-8-cineole, carvacrol, and eugenol, caused almost $100 \%$ adult mortality at doses as low as $5 \mu \mathrm{L} / \mathrm{L}$ air. Similar levels of adult beetle mortality were achieved with the remaining five components, (-)-linalool, $S$-(-)-limonene, (-)-menthone, and the two structural isomers of pinene, but only at relatively greater concentrations ( $\geq 10 \mu \mathrm{L} / \mathrm{L}$ air).

Previous studies have reported on the toxicity of essential oils to C. maculatus and other stored product insect pests [21, 29-31]. The toxicity of essential oils tested was attributed to the components of the oils [20, 32]. Fahimeh et al. [29] reported toxicity of essential oil of Zataria multiflora (Boiss) (Lamiaceae) to C. maculatus at doses as low as $9 \mu \mathrm{L} / \mathrm{L}$ air 24 hours after treatment. It is worth mentioning that Zataria multiflora is a major source of carvacrol, which was also toxic to adult $C$. maculatus causing $100 \%$ mortality at $10 \mu \mathrm{L} / \mathrm{L}$ air in the present study. However, our $\mathrm{LD}_{50}$ for carvacrol $(0.6 \mu \mathrm{L} / \mathrm{L}$ air) (Figure 2) was about one-fourteenth of the $\mathrm{LD}_{50}$ value $(8.81 \mu \mathrm{L} / \mathrm{L}$ air $)$ reported by Fahimeh et al. [29]. Sharifian et al. [33] reported that oil extracts of Mugwort (Artemisia vulgaris L.), a major source of (+)- $\alpha$-pinene, were effective against $C$. maculatus. The estimated $\mathrm{LD}_{50}$ of $53 \mu \mathrm{L} / \mathrm{L}$ air at 24 hours was greater than the $\mathrm{LD}_{50}$ of $31.4 \mu \mathrm{L} / \mathrm{L}$ air at 24 hours obtained in our study using the neat form of $(+)-\alpha$-pinene. Arezo et al. [34] estimated $\mathrm{LD}_{50}$ of $24 \mu \mathrm{L} / \mathrm{L}$ air for (-)-linalool at 24 hours which was almost three times greater than the $\mathrm{LD}_{50}$ value of 


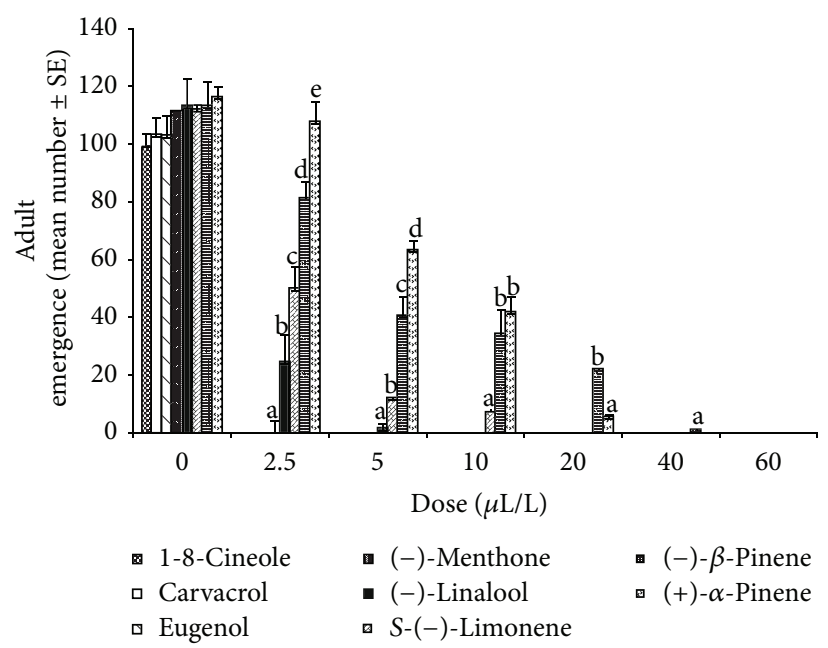

FIGURE 5: Number of adult C. maculatus that emerged from eggs laid during fumigation with essential oil monoterpenes. ANOVA and Tukey's HSD test compared monoterpenes at each dose tested.

$8.9 \mu \mathrm{L} / \mathrm{L}$ air obtained for $(-)$-linalool in this present study. Similarly, the $13.2 \mu \mathrm{L} / \mathrm{L}$ air we obtained for $S$-(-)-limonene was eight times less than the $\mathrm{LD}_{50}$ value of $106 \mu \mathrm{L} / \mathrm{L}$ air obtained by Ramin and Yunes [31] with essential oils from the peels of Citrus sinensis (L.). Synthetic (pure) monoterpenes were tested in the present study and that may explain the much lower $\mathrm{LD}_{50}$ values compared to that reported in the earlier studies with whole essential oils. Furthermore, it is plausible that other components of essential oils may have interacted to reduce efficacy of the monoterpenes in the whole oils tested.

Earlier studies have also revealed toxicities of the monoterpenes we tested in this study to other stored grain pests [35-38]. Carvacrol and 1-8-cineole were found toxic to Tenebrio molitor (F.) at $\mathrm{LD}_{50}$ of 5.52 and $5.71 \mu \mathrm{L}$, respectively [36]. Limonene had varied level of toxicity to Rhyzopertha dominica (F.), Sitophilus oryzae (L.), and Tribolium castaneum (Herbst.) [35]. Ogendo et al. [37] reported that mortalities of S. oryzae, $R$. dominica, T. castaneum, Oryzaephilus surinamensis (L.), and Callosobruchus chinensis (F.) with $\alpha$ and $\beta$-pinenes ranged between $7.3-100 \%$ and $32.5-100 \%$, respectively. (-)-Linalool and (-)-menthone were also found to cause $100 \%$ mortality of S. zeamais (L.) at $30 \mu \mathrm{L} / \mu \mathrm{g}$ [38]. Source and purity may affect bioactivity of essential oils and the monoterpenes, and also age, size, sex, insect order, and species influence insects' susceptibility to chemicals [34]. Any of the above-mentioned factors or a combination of two or more of these factors may have accounted for the differences between the results obtained in the present study and the previous related studies.

4.2. Oviposition Deterrence and Adult Emergence. Two of the eight treatments, 1-8-cineole and carvacrol, completely deterred oviposition. (-)-Menthone and eugenol treated seeds had significantly fewer eggs while seeds treated with $(+)-\alpha$-pinene and $(-)-\beta$-pinene had the highest numbers of eggs. Among the six treatments which did not cause complete prevention of oviposition, eugenol and (-)-menthone completely inhibited adult emergence. The two pinene isomers had greater numbers of adult emergence. Previous related studies have tested the toxicity of crude essential oils to eggs of C. maculatus laid during fumigation [39, 40], but we are not aware of any studies that specifically tested synthetic (pure) essential oil components. Eman and Abass [40], in their study of efficacy of five essential oils against C. maculatus, reported significant reduction in oviposition with $1 \%$ acetone solution of Mentha rotundifolia (L.) and Mentha pulegium (L.). M. rotundifolia oil contains a low percentage $(8.5 \%)$ of $1-8$-cineole, while $M$. pulegium oil has $0.05,0.2$, and $0.4 \%$ of $(+)-\alpha$-pinene, $(-)-\beta$-pinene, and $S$ - $(-)$ limonene, respectively. Interestingly, $S$ - $(-)$-limonene and the two isomers of pinene were not effective in the present study as oviposition deterrent or in preventing adult emergence even at high doses. Oil of Elettaria cardamomum (L.), a major source of 1-8-cineole (55.7\%), also reduced oviposition by C. maculatus [40]. Other components of the oil may have interacted to lower the efficacy of 1-8-cineole content. Essential oils and their components possess low or no toxicity against vertebrates $[20,41,42]$. Acute toxicity $\left(\mathrm{LD}_{50}\right)$ of 18 -cineole $(2,480 \mathrm{mg} / \mathrm{kg} \mathrm{BW})$, eugenol $(2,680 \mathrm{mg} / \mathrm{kg} \mathrm{BW})$, and linalool $(>1000 \mathrm{mg} / \mathrm{kg} \mathrm{BW})$ in rats is far less than that of some approved plant-based pesticides like pyrethrins (300$350 \mathrm{mg} / \mathrm{kg} \mathrm{BW}$ ) and pyrethrum (1500 mg/kg BW) [20, 32, 43]. Besides, they are easily biodegradable; hence, the use of these oil components to protect cowpea seeds may not constitute problems to man and environment.

In summary, our results showed that 1-8-cineole, (-)menthone, carvacrol, and eugenol are highly toxic to adult and egg stages of $C$ maculatus, even at low concentrations. Vapor pressure was the best predictor of toxicity of the essential oil components. While 1-8-cineole and carvacrol completely prevented oviposition, some eggs were laid on seeds treated with eugenol and (-)-menthone but the eggs did not develop to adults. These suggest that 1-8-cineole, carvacrol, eugenol, or (-)-menthone can be used to prevent 
population build-up of C. maculatus in stored cowpea. The results also showed that fumigation with a single lethal dose or repeated treatment with $(-)$-linalool, $S$ - $(-)$-limonene, $(+)$ $\alpha$-pinene, and (-)- $\beta$-pinene may be necessary for effective control of $C$. maculatus in stored cowpea. Essential oil components may also be combined with modified atmosphere or other tactics such as Purdue Improved Bag to achieve effective protection of stored cowpea.

\section{Conflict of Interests}

The authors declare that there is no conflict of interests regarding the publishing of this paper.

\section{Acknowledgments}

The authors would like to acknowledge The Schlumberger Foundation Inc., Houston, Texas, for supporting this research through a fellowship to OEA. The authors thank Marla J. Eva for laboratory assistance.

\section{References}

[1] B. B. Singh, H. A. Ajeigbe, S. A. Tarawali, S. Fernandez-Rivera, and M. Abubakar, "Improving the production and utilization of cowpea as food and fodder," Field Crops Research, vol. 84, no. 1-2, pp. 169-177, 2003.

[2] S. R. Singh, L. E. N. Jackai, J. H. R. Dos Santo, and C. B. Adalla, "Insect pest of Cowpea," in Insect Pest of Food Legumes, S. R. Singh, Ed., pp. 43-80, John Wiley \& Sons, Chichester, UK, 1990.

[3] N. Z. Dimetry, S. El-Gengaihi, and A. M. E. Abd El-Salam, "Protection of stored cowpea from Callosobruchus maculatus (F.) attack by some plant extracts formulations in different storage sacks," Herba Polonica, vol. 53, pp. 71-84, 2007.

[4] A. Sanon, L. C. B. Dabiré, A. P. Ouédraogo, and J. Huignard, "Field occurrence of bruchid pests of cowpea and associated parasitoids in a sub humid zone of Burkina Faso: importance on theinfestation of two cowpea varieties at harvest," Journal of Plant Pathology, vol. 4, no. 1, pp. 14-20, 2005.

[5] P. A. Edde and C. I. Amatobi, "Seed coat has no value in protecting cowpea seed against attack by Callosobruchus maculatus (F.)," Journal of Stored Products Research, vol. 39, no. 1, pp. 1-10, 2003.

[6] G. Forget, "Balancing the need for pesticides with the risk to human health," in Impact of Pesticide Use on Health in Developing Countries, G. Forget, T. Goodman, and A. de Villiers, Eds., vol. 2, International Development Research Centre, Ottawa, Canada, 1993.

[7] R. Meadows, "News overview: researchers develop alternatives to methyl bromide fumigation," California Agriculture, vol. 67, no. 3, pp. 125-127, 2013.

[8] US Environmental Protection Agency (US EPA), Phosphine. Integrated Risk Information Service (IRIS), US EPA, Washington, DC, USA, 2003.

[9] M. K. Mahmud, M. M. H. Khan, M. Husain, M. I. Alam, and M. S. I. Afrad, "Toxic effects of different plant oils on pulse beetle Callosobruchus chinensis Linn. (Coleoptera: Bruchidae)," Journal of Asiatic Society of Bangladesh: Science, vol. 28, no. 1, pp. 11-18, 2002.
[10] F. E. Dayan, C. L. Cantrell, and S. O. Duke, "Natural products in crop protection," Bioorganic and Medicinal Chemistry, vol. 17, no. 12, pp. 4022-4034, 2009.

[11] M.-J. Sim, D.-R. Choi, and Y.-J. Ahn, "Vapor phase toxicity of plant essential oils to Cadra cautella (Lepidoptera: Pyralidae)," Journal of Economic Entomology, vol. 99, no. 2, pp. 593-598, 2006.

[12] M. Isman, C. Machial, S. Miresmailli, and L. Bainard, "Essential oil-based pesticides: new insights from old chemistry," in Pesticides Chemistry, H. Ohkawa, H. Miyagawa, and P. Lee, Eds., pp. 201-209, Wiley-VCH, Weinheim, Germany, 2007.

[13] D. P. Papachristos and D. C. Stamopoulos, "Selection of Acanthoscelides obtectus (Say) for resistance to lavender essential oil vapour," Journal of Stored Products Research, vol. 39, no. 4, pp. 433-441, 2003.

[14] U. R. Pathipati, "Fumigant and contact toxic potential of essential oils from plant extracts against stored product pests," Journal of Biopesticides, vol. 5, no. 2, pp. 120-128, 2012.

[15] D. Suthisut, P. G. Fields, and A. Chandrapatya, "Fumigant toxicity of essential oils from three Thai plants (Zingiberaceae) and their major compounds against Sitophilus zeamais, Tribolium castaneum and two parasitoids," Journal of Stored Products Research, vol. 47, no. 3, pp. 222-230, 2011.

[16] C. O. Adedire and O. E. Ajayi, "Potential of sandbox, Hura crepitans L. seed oil for protection of cowpea seeds from Callosobruchus maculatus (F.) (Coleoptera: Bruchidae) infestation," Journal of Plant Diseases and Protection, vol. 110, no. 6, pp. 602610, 2003.

[17] F. A. Lolestani and N. Shayesteh, "Fumigant toxicity of Ziziphora clinopodioides (Boiss.) (Lamiaceae) against adults and eggs of Callosobruchus maculatus (Fab.) (Coleoptera: Bruchidae)," Journal of Biological Sciences, vol. 9, no. 1, pp. 92-95, 2009.

[18] M. E. A. Ahmed, "Fumigant toxicity of seven essential oils against the cowpea weevil, Callosobruchus maculatus (F.) and the rice weevil, Sitophilus oryzae (L.)," Egyptian Academic Journal of Biological Sciences, vol. 2, pp. 1-6, 2010.

[19] S. Lee, R. Tsao, C. Peterson, and J. R. Coats, "Insecticidal activity of monoterpenoids to western corn rootworm (Coleoptera: Chrysomelidae), twospotted spider mite (Acari: Tetranychidae), and house fly (Diptera: Muscidae)," Journal of Economic Entomology, vol. 90, no. 4, pp. 883-892, 1997.

[20] O. Koul, S. Walia, and G. S. Dhaliwal, "Essential oils as green pesticides: potential and constraints," Pesticide International, vol. 4, no. 1, pp. 63-84, 2008.

[21] A. K. Phillips and A. G. Appel, "Fumigant toxicity of essential oils to the German cockroach (Dictyoptera: Blattellidae)," Journal of Economic Entomology, vol. 103, no. 3, pp. 781-790, 2010.

[22] M. B. Isman, "Plant essential oils for pest and disease management," Crop Protection, vol. 19, no. 8-10, pp. 603-608, 2000.

[23] E. Enan, "Insecticidal activity of essential oils: octopaminergic sites of action," Comparative Biochemistry and Physiology C: Toxicology and Pharmacology, vol. 130, no. 3, pp. 325-337, 2001.

[24] C. Regnault-Roger, C. Vincent, and J. T. Arnason, "Essential oils in insect control: low-risk products in a high-stakes world," Annual Review of Entomology, vol. 57, pp. 405-424, 2012.

[25] J. A. Johnson and K. A. Valero, "Use of commercial freezers to control cowpea weevil, Callosobruchus maculatus (Coleoptera: Bruchidae), in organic garbanzo beans," Journal of Economic Entomology, vol. 96, no. 6, pp. 1952-1957, 2003.

[26] E. O. Onagbola and H. Y. Fadamiro, "Electroantennogram and behavioral responses of Pteromalus cerealellae to odor stimuli 
associated with its host, Callosobruchus maculatus," Journal of Stored Products Research, vol. 47, no. 2, pp. 123-129, 2011.

[27] D. Rees, Insects of Stored Products, CIRO Publishing, Collingwood, Australia, 2004.

[28] SPSS, Statistical Package for Social Sciences, 16.0 for windows. SPSS Inc, Chicago, Ill, USA, 2008.

[29] R. Fahimeh, M. Saeid, S. Mahmood, and A. Habib, "Chemical composition and insecticidal activity of essential oil of Zataria multiflora Boiss. (Lamiaceae) against Callosobruchus maculatus (F.) (Coleoptera : Bruchidae)," IOBC-WPRS Bulletins, vol. 69, pp. 281-288, 2011.

[30] V. Rozman, I. Kalinovic, and Z. Korunic, "Toxicity of naturally occurring compounds of Lamiaceae and Lauraceae to three stored-product insects," Journal of Stored Products Research, vol. 43, no. 4, pp. 349-355, 2007.

[31] T. Ramin and K. Yunes, "Evaluation of fumigant toxicity of orange peel Citrus sinensis (L.) essential oil against three stored product insects in laboratory condition," Munis Entomology and Zoology, vol. 7, pp. 352-358, 2012.

[32] D. R. Batish, H. P. Singh, R. K. Kohli, and S. Kaur, "Eucalyptus essential oil as a natural pesticide," Forest Ecology and Management, vol. 256, no. 12, pp. 2166-2174, 2008.

[33] I. Sharifian, S. M. Hashemi, and A. Darvishzadeh, "Fumigant toxicity of essential oil of Mugwort (Artemisia vulgaris L.) against three major stored product beetles," Archives of Phytopathology and Plant Protection, vol. 46, no. 4, pp. 445-450, 2013.

[34] A. Davoudi, N. Shayesteh, D. Shirdel, and A. Hosseinzadeh, "Effect of diethyl maleate on toxicity of linalool against two stored product insects in laboratory condition," African Journal of Biotechnology, vol. 10, no. 48, pp. 9918-9921, 2011.

[35] A. K. Tripathi, V. Prajapati, S. P. S. Khanuja, and S. Kumar, "Effect of $d$-limonene on three stored-product beetles," Journal of Economic Entomology, vol. 96, no. 3, pp. 990-995, 2003.

[36] R. K. Lima, M. D. G. Cardoso, J. C. Moraes, S. M. Carvalho, V. G. Rodrigues, and L. G. L. Guimarães, "Chemical composition and fumigant effect of essential oil of Lippia sidoides cham. and monoterpenes against Tenebrio molitor (L.) (Coleoptera: Tenebrionidae)," Ciência e Agrotecnologia, vol. 35, no. 4, pp. 664-671, 2011.

[37] J. O. Ogendo, A. L. Deng, M. Kostyukovsky et al., "Fumigant toxicity of five essential oil constituents against major storedproduct insect pests of food grains. Research and application summary," in Proceedings of the 2nd RUFORUM Biennial Meeting, Entebbe, Uganda, September 2010.

[38] E. Yildirim, B. Emsen, and S. Kordali, "Insecticidal effects of monoterpenes on Sitophilus zeamais Motschulsky (Coleoptera: Curculionidae )," Journal of Applied Botany and Food Quality, vol. 86, pp. 198-204, 2013.

[39] E. A. Eman and M. H. Abass, "Chemical composition and efficiency of five essential oils against the pulse beetle Callosobruchus maculatus (F.) on Vigna radiata seeds," The AmericanEurasian Journal of Agriculture and Environmental Science, vol. 8, pp. 411-419, 2010.

[40] H. Abbasipour, M. Mahmoudvand, F. Rastegar, and M. H. Hosseinpour, "Fumigant toxicity and oviposition deterrency of the essential oil from cardamom, Elettaria cardamomum, against three stored-product insects," Journal of Insect Science, vol. 11, article 165, 2011.

[41] E. Enan, M. Beigler, and A. Kende, "Insecticidal action of terpenes and phenols to cockroaches: effect on octopamine receptors," in Proceedings of the International Symposium on Plant Protection, Gent, Belgium, 1998.

[42] F. Bakkali, S. Averbeck, D. Averbeck, and M. Idaomar, "Biological effects of essential oils-a review," Food and Chemical Toxicology, vol. 46, no. 2, pp. 446-475, 2008.

[43] J. E. Casida and G. B. Quistad, Pyrethrum Flowers: Production, Chemistry, Toxicology and Uses, Oxford University Press, Oxford, UK, 1995. 

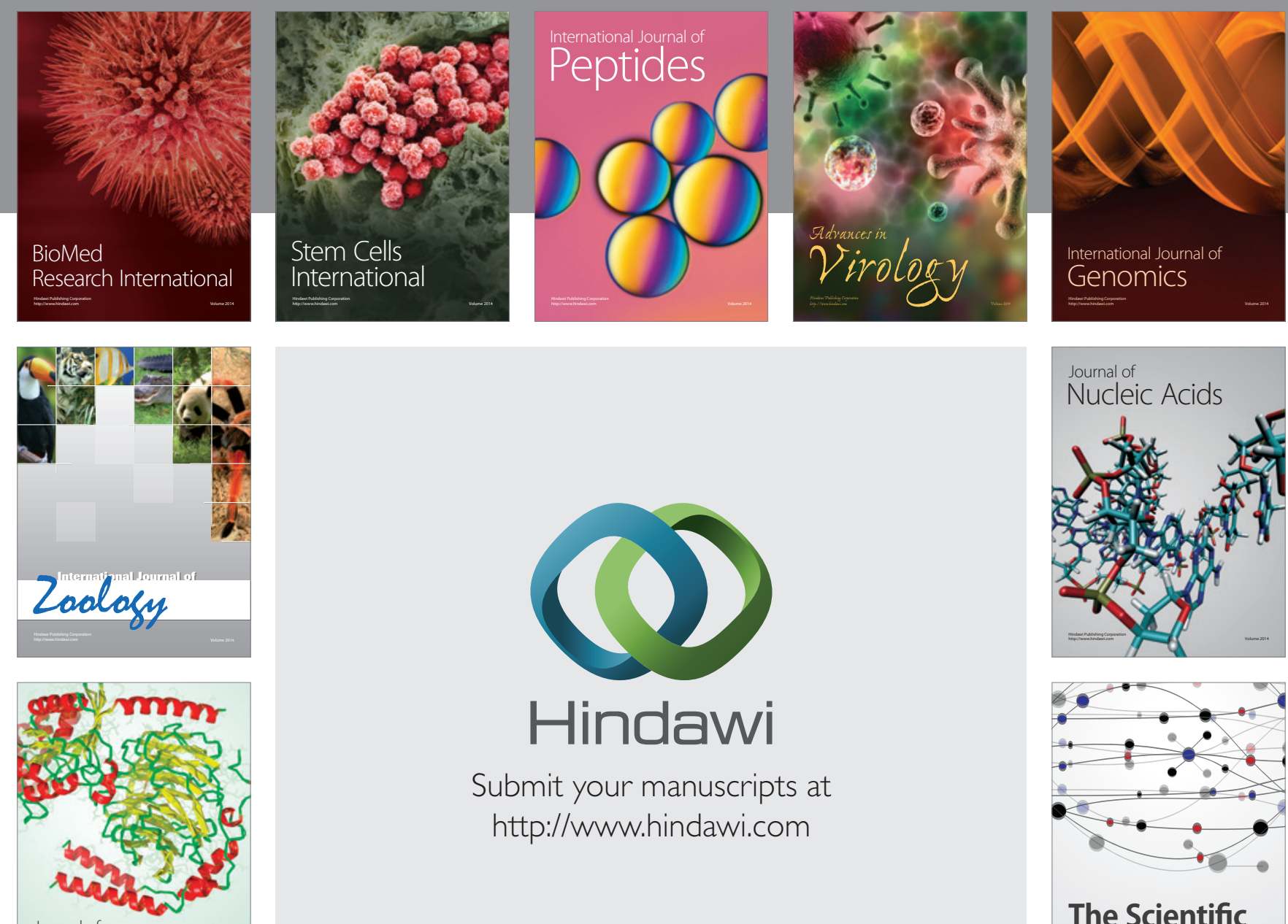

Submit your manuscripts at

http://www.hindawi.com

Journal of
Signal Transduction
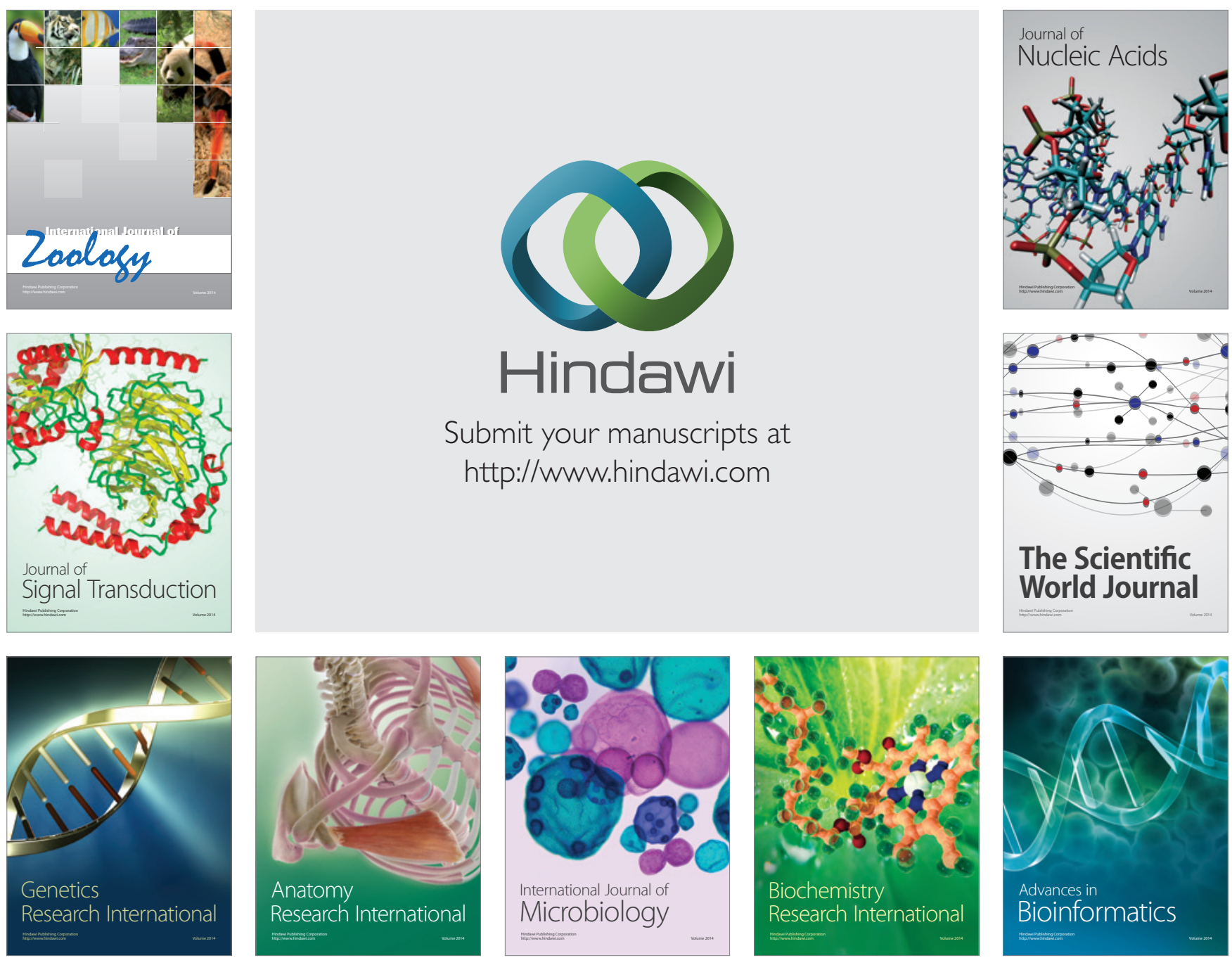

The Scientific World Journal
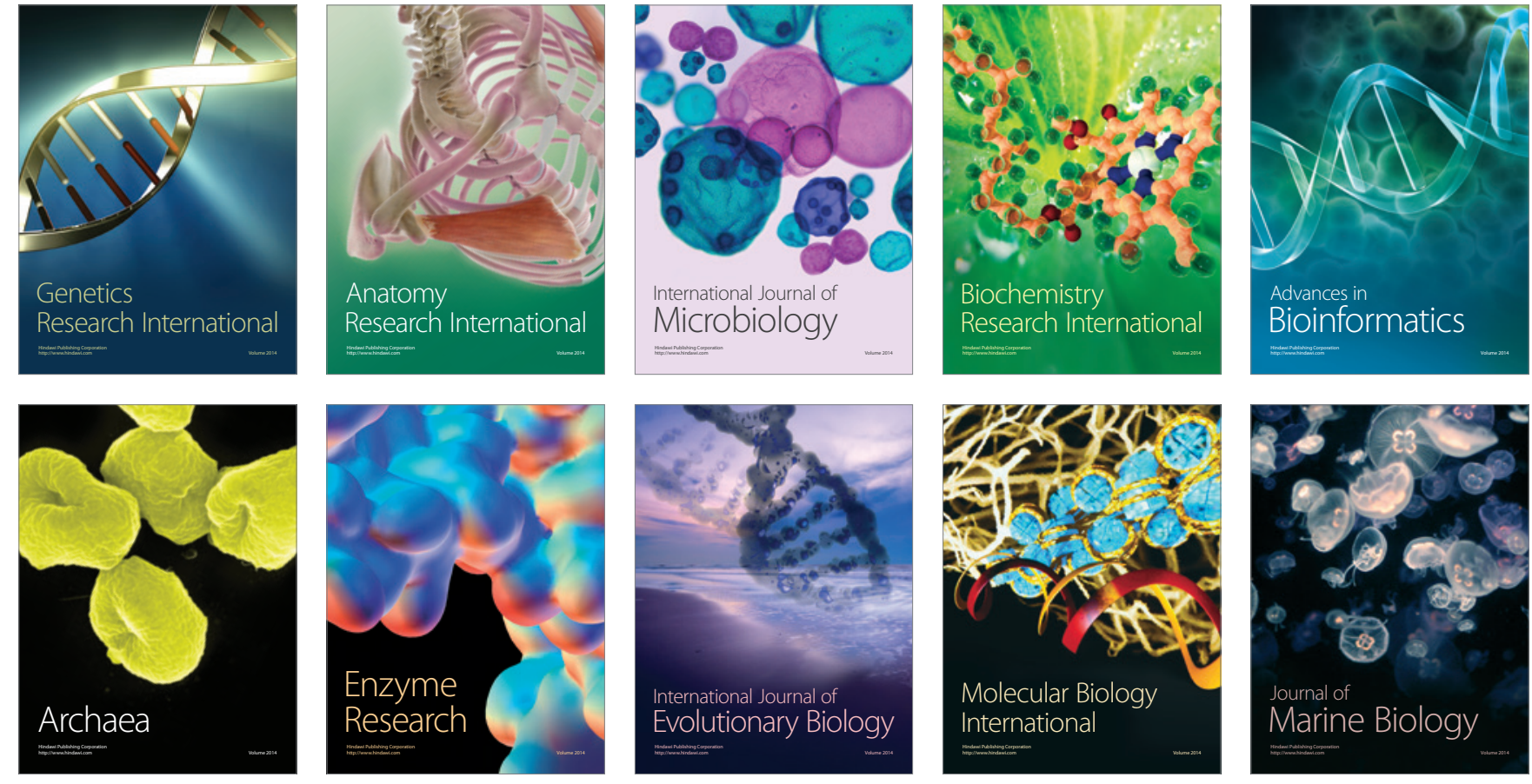